\title{
Potential adverse effects of botanical supplementation in high-fat-fed female mice
}

\author{
Scott Fuller ${ }^{1,2}$, Yongmei Yu' ${ }^{1}$, Tamra Mendoza ${ }^{1}$, David M. Ribnicky ${ }^{3}$, William T. Cefalu ${ }^{1}$ and Z. Elizabeth Floyd ${ }^{1 *}$ (D)
}

\begin{abstract}
Background: Insulin resistance underlies metabolic syndrome and is associated with excess adiposity and visceral fat accumulation, which is more frequently observed in males than females. However, in young females, the prevalence of metabolic syndrome is rising, mainly driven by accumulation of abdominal visceral fat. The degree to which sex-related differences could influence the development of insulin resistance remains unclear, and studies of potential therapeutic strategies to combat metabolic syndrome using rodent models have focused predominantly on males. We therefore evaluated the effects of two nutritional supplements derived from botanical sources, an extract of Artemisia dracunculus L. (termed PMI5011) and Momordica charantia (commonly known as bitter melon), on female mice challenged with a high-fat diet in order to determine if dietary intake of these supplements could ameliorate obesity-induced insulin resistance and metabolic inflexibility in skeletal muscle.

Methods: Body composition, physical activity and energy expenditure, fatty acid oxidation, insulin signaling, and gene and protein expression of factors controlling lipid metabolism and ectopic lipid accumulation were evaluated in female mice fed a high-fat diet supplemented with either PMI5011 or bitter melon. Statistical significance was assessed by unpaired two-tailed $t$ test and repeated measures ANOVA.
\end{abstract}

Results: PMI5011 supplementation resulted in increased body weight and adiposity, while bitter melon did not induce changes in these parameters. Pyruvate tolerance testing indicated that both supplements increased hepatic glucose production. Both supplements induced a significant suppression in fatty acid oxidation in skeletal muscle homogenates treated with pyruvate, indicating enhanced metabolic flexibility. PMI5011 reduced lipid accumulation in skeletal muscle, while bitter melon induced a downward trend in lipid accumulation in the skeletal muscle and liver. This was accompanied by transcriptional regulation of autophagic genes by bitter melon in the liver.

Conclusions: Data from the current study indicates that dietary supplementation with PMI5011 and bitter melon evokes a divergent, and generally less favorable, set of metabolic responses in female mice compared to effects previously observed in males. Our findings underscore the importance of considering sex-related variations in responses to dietary supplementation aimed at combating metabolic syndrome.

Keywords: Sex, Botanical, Skeletal muscle, Insulin, Metabolic syndrome, Liver, Obesity

\footnotetext{
* Correspondence: elizabeth.floyd@pbrc.edu

${ }^{1}$ Pennington Biomedical Research Center, Louisiana State University System,

Baton Rouge, LA 70808, USA

Full list of author information is available at the end of the article
}

(c) The Author(s). 2018 Open Access This article is distributed under the terms of the Creative Commons Attribution 4.0 International License (http://creativecommons.org/licenses/by/4.0/), which permits unrestricted use, distribution, and reproduction in any medium, provided you give appropriate credit to the original author(s) and the source, provide a link to the Creative Commons license, and indicate if changes were made. The Creative Commons Public Domain Dedication waiver (http://creativecommons.org/publicdomain/zero/1.0/) applies to the data made available in this article, unless otherwise stated. 


\section{Background}

The prevalence of metabolic syndrome (MetS) has risen to epidemic proportions in recent decades and constitutes an emergent threat to global public health [1-3]. MetS is characterized by abdominal obesity, insulin resistance, dyslipidemia, and hypertension; these factors predispose individuals to greater risk for cardiovascular disease, chronic kidney disease, and several types of cancer [4-7]. Although research effort focused on MetS continues to intensify as the disease burden associated with the condition becomes ever more acute, an issue that remains relatively unclear is the extent to which MetS differentially affects males versus females $[8,9]$. In light of evidence that there are sex-related differences in the prevalence and pathophysiology of MetS, research specifically evaluating MetS in females offers the potential for developing sex-specific treatment modalities for chronic diseases including obesity, cardiovascular, and metabolic diseases $[10,11]$. However, the research undertaken thus far in both human and animal models has focused primarily on males [8]. Thus, there remains a relatively underserved need for investigation into MetS specifically in females.

Current recommendations for the prevention and treatment of MetS emphasize lifestyle modifications that include dietary changes, weight loss, and exercise [12]. However, despite persistent advice to the public emphasizing the importance of lifestyle factors in the prevention and management of MetS, the rising prevalence of the syndrome and its associated pathologies is a testament to the difficulties encountered in successfully implementing long-term behavioral changes. Pharmacotherapy has been employed with varying degrees of success, although disadvantages associated with prolonged use of pharmaceuticals include side effects, cost, and public access [13, 14], which is a particularly acute problem in the developing world where the incidence of MetS is escalating at an alarming rate and availability of pharmaceuticals can be a limiting factor [15]. Natural products derived from food sources therefore represent an attractive complementary therapy for the treatment of MetS due to their relative safety and tolerability compared to several of the drugs currently available, although vigilance remains necessary to ensure proper safety standards for nutritional supplements in the marketplace [16, 17].

Several species of the plant genus Artemisia have demonstrated potential for ameliorating MetS in laboratory studies [18-20]. In particular, Artemisia dracunculus L., or Russian tarragon, is a perennial herb with a documented history of medicinal use as an anti-diabetic [21]. Previous studies in our laboratory provide evidence that an ethanolic extract of A. dracunculus L. termed PMI5011 favorably modulates insulin signaling, lipid metabolism, and glucose homeostasis primarily via effects on skeletal muscle both in vitro and in obese male mice with established insulin resistance [22-25]. We recently extended these findings by demonstrating that early dietary supplementation with PMI5011 in male mice protects against the development of insulin resistance and ectopic lipid accumulation in the skeletal muscle and liver independent of any changes in adiposity or body mass [26]. Momordica charantia, commonly known as bitter melon, has been demonstrated to have anti-hyperglycemic and hypolipidemic [27, 28] effects and is a staple of the traditional diet in Okinawa, where rates of mortality and morbidity due to chronic diseases are among the lowest in the world [29]. Evidence from mechanistic studies in diabetic rodents indicates that bitter melon enhances insulin sensitivity by decreasing serum levels of the pro-inflammatory modulators tumor necrosis factor-alpha (TNF- $\alpha$ ) and interleukin-6 (IL-6), decreasing expression of suppressor of cytokine signaling-3 (SOCS-3) and c-Jun N-terminal kinase (JNK), and augmenting insulin-stimulated tyrosine phosphorylation of the insulin receptor substrate-1 (IRS-1) [27, 30]. Multiple studies in male rodents from our laboratories and others demonstrate that bioactives in bitter melon improve insulin sensitivity, possibly via reduced skeletal muscle and hepatic lipid accumulation [31-33]. The effect of bitter melon extract on hepatic lipids is attributed to reduced glucose production and lipid synthesis in the liver [34].

While experimental evidence demonstrates that PMI5011 and bitter melon favorably modulate insulin responsiveness and lipid metabolism in male rodents $[26,35]$, sex differences in the prevalence and pathogenesis of MetS raise the possibility that females might respond differently to dietary intervention. Given the current scarcity of data in females, we sought to evaluate the effectiveness of PMI5011 and bitter melon in female mice in order to clarify whether sex differences in the response to botanical dietary supplementation might be evident. In the present study, we evaluated the hypothesis that dietary supplementation with PMI5011 or bitter melon prior to the onset of high-fat diet-induced obesity prevents development of high-fat diet-related insulin resistance in female $\mathrm{C} 57 \mathrm{BL} / 6$ mice. The novel results reported herein indicate that female mice respond in a generally less favorable manner to supplementation with PMI5011 and bitter melon compared to the pattern previously reported in males [26]. The findings of the present study therefore indicate that sex is an important biological variable that merits serious consideration when evaluating the safety and efficacy of dietary interventions aimed at combating metabolic syndrome.

\section{Methods}

\section{Sourcing and characterization of PMI5011 extract}

The PMI5011 botanical extract from Artemisia dracunculus L. was provided by the Botanical and Dietary Supplement Research Center at Pennington Biomedical Research Center. Bitter melon was obtained from Verdure Sciences 
(Noblesville, IN). Detailed information about quality control, preparation, and biochemical characterization of PMI5011 has been previously reported [24, 25, 36-40].

\section{Experimental animals}

Reproductively intact female C57BL/6J mice were obtained from Jackson Laboratories (Bar Harbor, ME). The estrous cycle was not evaluated at the end of the 4-month study as evidence shows estrous cycle stage does not significantly contribute to variability of molecular or metabolic outcomes measured in female mice [41]. All animal experiments were approved by the Pennington Biomedical Research Center Animal Care and Use Committee (protocol \#922). The animals were singly housed with a 12 -h light-dark cycle at $24{ }^{\circ} \mathrm{C}$. At 4 weeks of age, mice of similar body weight were randomly assigned ( $n=14$ /group) to a defined low-fat diet (LFD; $10 \% \mathrm{kcal}$ fat, Research Diets, \#D12450H) or the low-fat diet supplemented with $1 \% w / w$ PMI5011 or bitter melon. After 4 weeks, the LFD only-fed mice were switched to a high-fat diet (HFD; 45\% kcal fat, Research Diets, \#D12451) and maintained as the control group. The mice fed a LFD supplemented with either PMI5011 or bitter melon were switched to the HFD supplemented with PMI5011 or bitter melon, formulated with the same mass botanical extract/kcal (equivalent to $1.2 \% \mathrm{w} / \mathrm{w}$ HFD) as contained in the LFD and were fed ad libitum for 3 months thereafter. The $45 \%$ fat content is similar to the fat intake (30-40\% of energy intake) for adult men and women in the USA [42]. Body weight and food intake were measured weekly, and body composition was measured bi-weekly by nuclear magnetic resonance (Bruker, Billerica, MA). Activity, food intake, and indirect calorimetry were measured at 12 weeks on each diet (TSE PhenoMaster). The mice were acclimated to the TSE chambers for 2 days prior to data collection over 4 days. At the end of the study, the mice were euthanized between 7 and 11 AM. Human insulin (Humulin, Eli Lilly, Indianapolis, IN) was administered to a subgroup of the control and botanical-supplemented mice (7/group) at a dose of $1.5 \mathrm{U} / \mathrm{kg} 10 \mathrm{~min}$ prior to euthanasia to assay insulin signaling.

\section{Glucose and insulin tolerance tests}

For the glucose (GTT) and insulin (ITT) tolerance tests, the amount of glucose or insulin administered was normalized to body weight, which did not vary significantly among groups (23.0干 $0.57 \mathrm{~g}$ body weight for females) at 10 weeks on the HFDs. Female mice were fasted $4 \mathrm{~h}$ prior to administering $2 \mathrm{~g} / \mathrm{kg}$ body weight of glucose/ mouse (GTT) or $1 \mathrm{U} / \mathrm{kg}$ body weight of insulin/mouse (HumulinR) (ITT) by intraperitoneal injection.

\section{Blood chemistry}

Fasting glucose levels were measured in whole blood using a Breeze2 glucometer (Bayer, Leverkusen, Germany). Fasting insulin levels were assayed via ELISA (Crystal Chem, Downers Grove, IL). Serum nonesterified fatty acids (Abcam, Cambridge, MA), triglycerides (Eagle Diagnostics, Cedar Hill, TX), and total cholesterol (Cell Biolabs, San Diego, CA) levels were assayed according to manufacturers' instructions. The index of homeostasis model assessment for insulin resistance, e.g., HOMA-IR [insulin $(\mathrm{mU} / \mathrm{L}) \times$ glucose $(\mathrm{mM}) / 22.5]$, of each animal was calculated from fasting glucose and insulin levels [43]. Triglyceride levels in the skeletal muscle and liver were assayed according to Folch et al. [44] and reported as milligrams per deciliter. Visible fat was carefully removed from the tissue before assaying triglyceride levels.

\section{Immunohistochemistry}

A portion of mixed gastrocnemius muscle and liver was fixed in $10 \%$ formalin, embedded in paraffin, and sectioned onto slides. The sections were hematoxylin and eosin (H\&E) stained and scanned (NanoZoomer Digital Pathology, Hamamatsu Corp., Bridgewater, NJ).

\section{Fatty acid oxidation assay}

Mixed gastrocnemius muscle homogenates were prepared as described [45]. Palmitate oxidation was assessed in the whole muscle homogenates as described by Hulver et al [46] with ${ }^{14} \mathrm{CO}_{2}$ collected over $60 \mathrm{~min}$. When present, pyruvate was added at a final concentration of $10 \mathrm{mM} . \mathrm{CO}_{2}$ levels were normalized to total protein and palmitate oxidation reported as $\mathrm{nmol} \mathrm{CO}_{2} / \mathrm{mg}$ protein $/ \mathrm{h}$.

\section{Analysis of protein expression}

Skeletal muscle and liver lysates were prepared from powdered tissue by homogenizing in $25 \mathrm{mM}$ HEPES, $\mathrm{pH}$ 7.4, 1\% Igepal CA630, $137 \mathrm{mM} \mathrm{NaCl}, 1 \mathrm{mM}$ PMSF, $10 \mu \mathrm{g} / \mathrm{ml}$ aprotinin, $1 \mu \mathrm{g} / \mathrm{ml}$ pepstatin, $5 \mu \mathrm{g} / \mathrm{ml}$ leupeptin, $10 \mathrm{mM} \mathrm{Na}{ }_{4} \mathrm{P}_{2} \mathrm{O}_{7}, 100 \mathrm{mM} \mathrm{NaF}$, and $2 \mathrm{mM} \mathrm{NaVO}_{4}$ using a Sonifier 450 homogenizer (VWR, Radnor, PA). The samples were centrifuged at $14,000 \times g$ for $10 \mathrm{~min}$ at $4{ }^{\circ} \mathrm{C}$. Protein concentrations were determined using a BCA assay (Thermo Fisher Scientific, Rockford, IL) according to the manufacturer's instructions. The tissue supernatants $(50 \mu \mathrm{g})$ were resolved by SDS-PAGE and subjected to immunoblotting using chemiluminescence detection (Thermo Fisher Scientific, Rockford, IL) and quantified as described [47]. Nitrocellulose membranes were incubated with antibodies for $1-2 \mathrm{~h}$ at room temperature or overnight at $4{ }^{\circ} \mathrm{C}$ as indicated. An additional file provides detailed information about each antibody used (see Additional file 1). 


\section{Analysis of gene expression}

Total RNA was purified from powdered the skeletal muscle tissue or liver using Direct-zol RNA MiniPrep (ZYMO Research, Irvine, CA). In each case, RNA (500 ng) was reverse transcribed using Multiscribe Reverse Transcriptase (Applied Biosystems, Thermo Fisher Scientific, Waltham, MA) with random primers at $37{ }^{\circ} \mathrm{C}$ for $2 \mathrm{~h}$. Real-time PCR was performed with PowerUP SYBR Green Master Mix (Applied Biosystems) according to the manufacturer's instructions, using the 7900 Real-Time PCR system and universal cycling conditions $\left(50{ }^{\circ} \mathrm{C}\right.$ for $2 \mathrm{~min} ; 95^{\circ} \mathrm{C}$ for $10 \mathrm{~min} ; 40$ cycles of $95{ }^{\circ} \mathrm{C}$ for $15 \mathrm{~s}$ and $60^{\circ} \mathrm{C}$ for $1 \mathrm{~min}$; followed by $95^{\circ} \mathrm{C}$ for $15 \mathrm{~s}, 60^{\circ} \mathrm{C}$ for $15 \mathrm{~s}$, and $95{ }^{\circ} \mathrm{C}$ for $15 \mathrm{~s}$ ). The assays were performed in triplicate, and the results were normalized to Cyclophilin B mRNA and analyzed using the $2^{-\Delta \Delta C \mathrm{~T}}$ method with the control diet used as the calibrator. The gene list is provided in an additional file (see Additional file 2).

\section{Statistical analysis}

Normal distribution of the data for glucose and insulin levels, food intake, and body weight was determined using the D'Agostino-Pearson omnibus K2 normality test. Western blot data was quantified using Un-Scan-It software (version 3, Silk Scientific). Statistical significance was determined using an unpaired two-tailed $t$ test or repeated measures ANOVA. All statistical analysis was carried out using JMP Pro13 (SAS Institute) and GraphPad Prism 5 software (GraphPad Software, La Jolla, CA). Variability is expressed as the mean \pm standard deviation.

\section{Results}

Effect of PMI5011 and bitter melon on body composition in female mice

A number of previous studies established that the ethanolic extract from A. dracunculus termed PMI5011 enhances insulin signaling in skeletal muscle and improves insulin sensitivity on a preexisting background of insulin resistance in vitro and in vivo in male mice $[22,24,25$, $48,49]$. To determine if high-fat diet-related insulin resistance can be prevented in female mice by dietary supplementation with either PMI5011 or bitter melon, we carried out a feeding study in female C56BL/6J mice given a LFD alone or supplemented with PMI5011 or bitter melon for 1 month beginning at 4 weeks of age. After 1 month, the diet was switched to a 45\% HFD alone or supplemented with PMI5011 or bitter melon and these diets were maintained for 3 months. As shown in Fig. 1a, c, PMI5011 supplementation resulted in a statistically significant increase in body weight due to increased adiposity unrelated to food intake in female mice. Bitter melon supplementation did not affect body

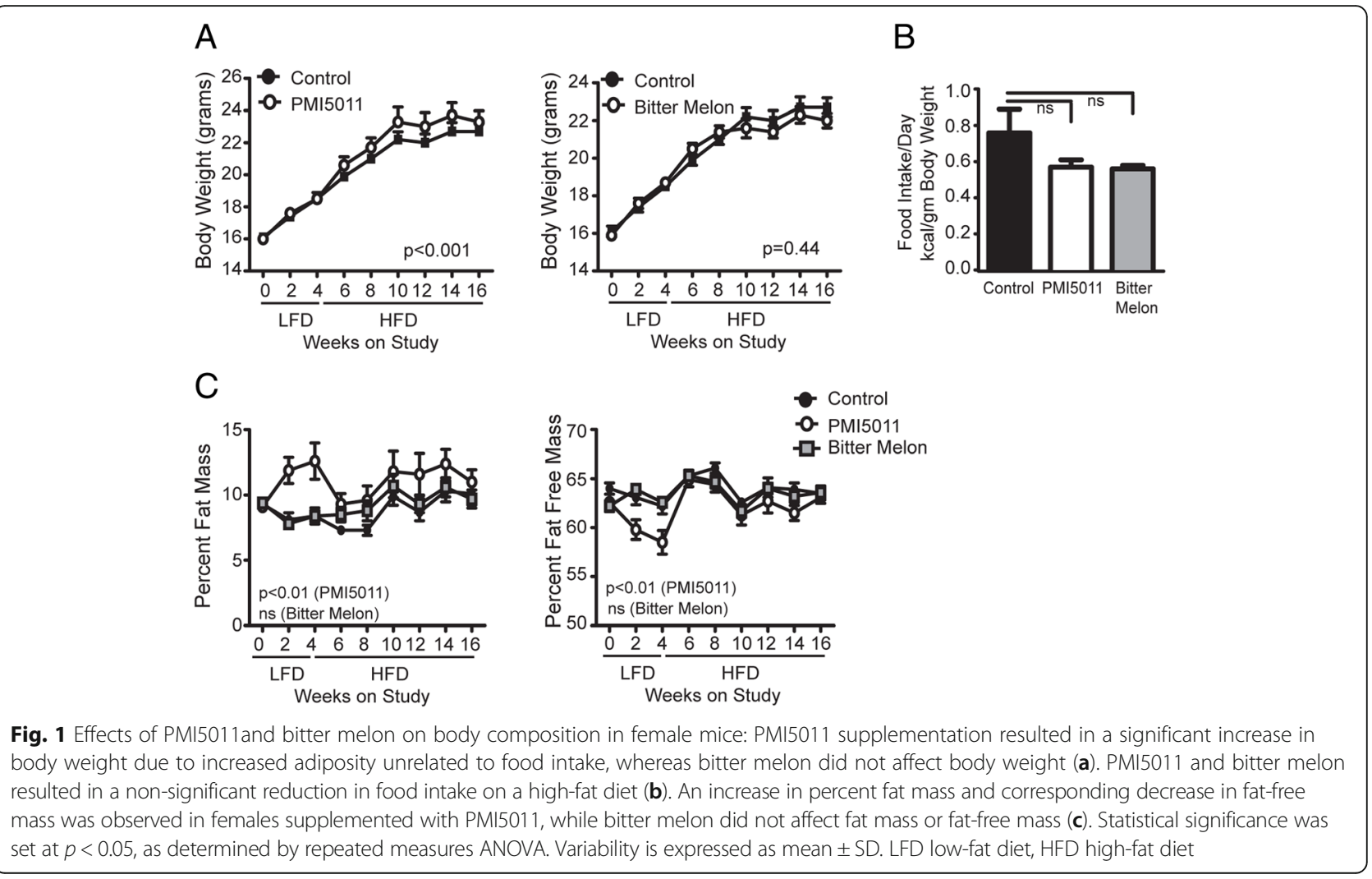


weight. Both PMI5011 and bitter melon supplementation resulted in a non-significant reduction in food intake in females on the HFD (Fig. 1b). While PMI5011 supplementation resulted in a significant increase in percent fat mass in females (Fig. 1c), bitter melon supplementation in female mice did not change body weight or body composition (Fig. 1a, c).

\section{Effect of PMI5011 and bitter melon on energy}

expenditure and substrate utilization in female mice

Our data on body weight and adiposity revealed that the female mice did not become obese in response to HFD, a finding that is consistent with other published data [50-52]. We then evaluated activity and energy expenditure to determine which of these factors could account for the resistance to weight gain and adiposity observed in our female mice. PMI5011 did not affect energy expenditure or activity, but we observed decreased activity and energy expenditure in response to bitter melon supplementation (Fig. 2). However, these small decreases in already high levels of activity and energy expenditure were not associated with body weight gain or increased adiposity. Neither botanical supplement significantly altered the respiratory exchange ratio (Fig. 2).

\section{Carbohydrate and lipid metabolism in response to PMI5011 and bitter melon supplementation}

We next assayed the effects of PMI5011 and bitter melon on glucose homeostasis and insulin sensitivity in female mice via glucose and insulin tolerance testing along with fasting glucose and insulin levels. Although neither glucose nor insulin tolerance testing shows any statistically significant effect on AUC for glucose for either botanical supplement (Fig. 3a, b), we observed that glucose levels were somewhat higher at the later time points for both PMI5011 and bitter melon in insulin tolerance testing (Fig. 3b). This raised the possibility that the supplements induced alterations in hepatic glucose production, which we assessed by conducting pyruvate tolerance testing. Repeated measures ANOVA indicated that both supplements significantly increased glucose production, consistent with increased gluconeogenesis (Fig. 3c). However, fasting serum glucose and insulin levels indicate that although neither supplement significantly altered blood glucose concentrations, PMI5011 induced an increase in fasting serum

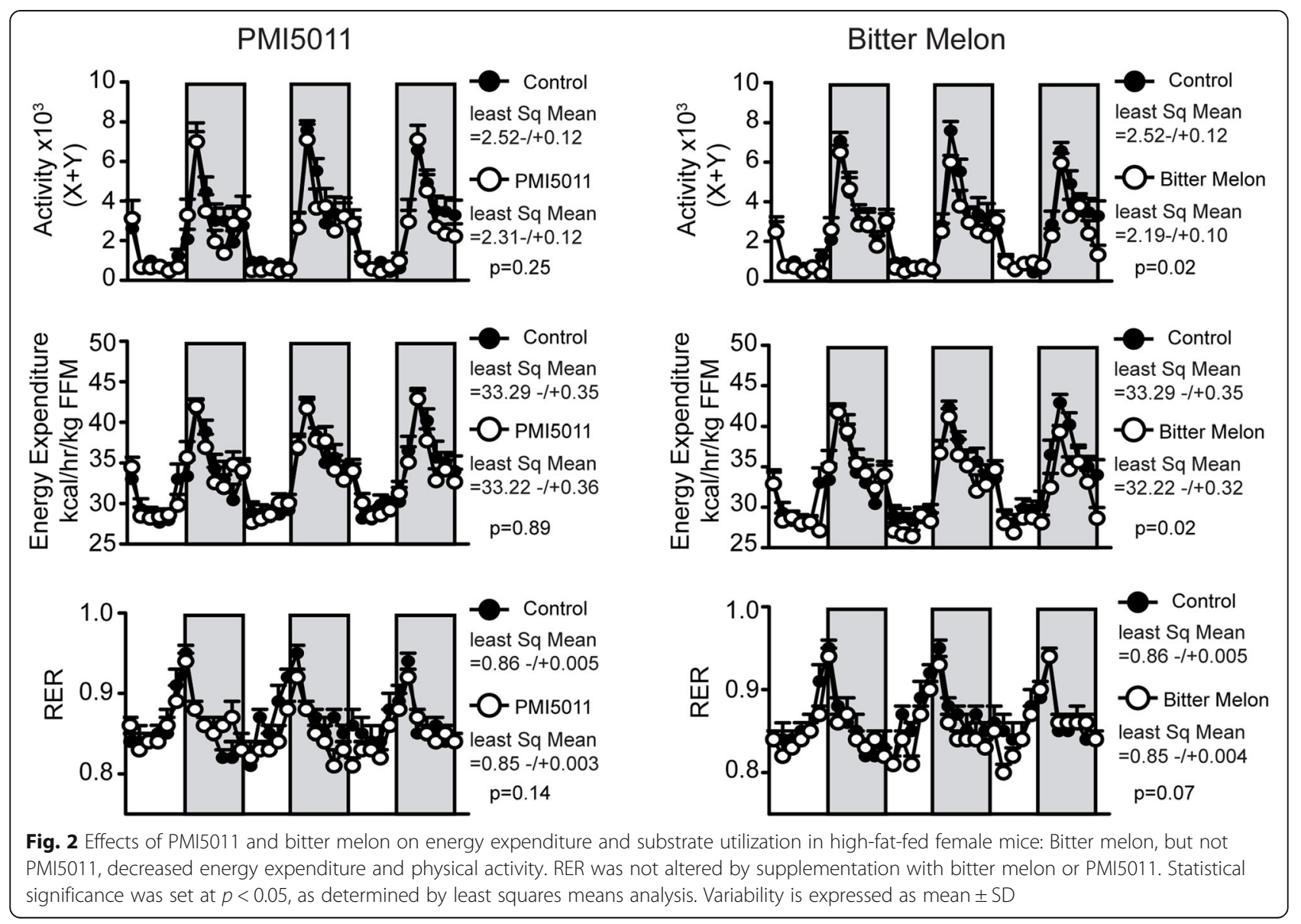



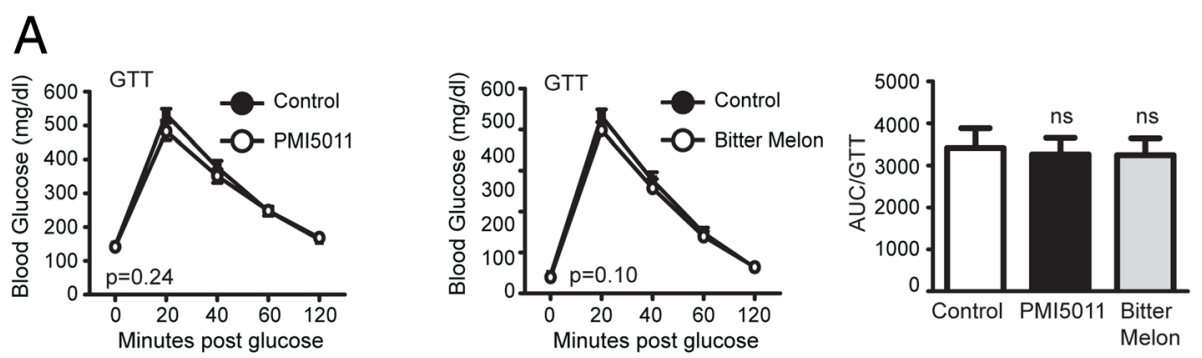

B
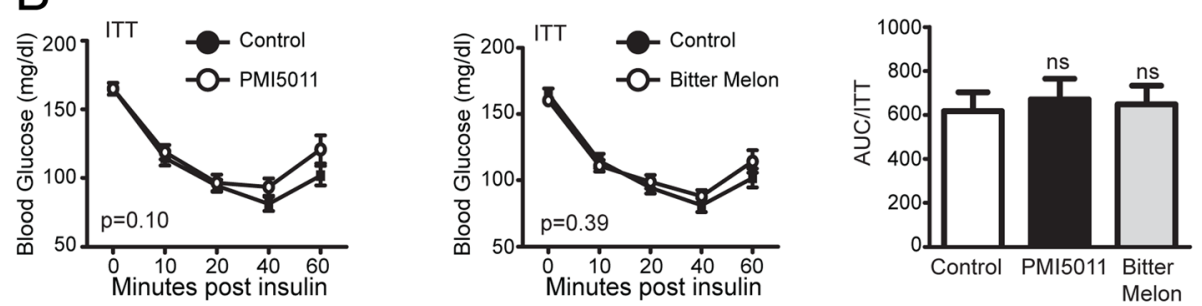

\section{C}
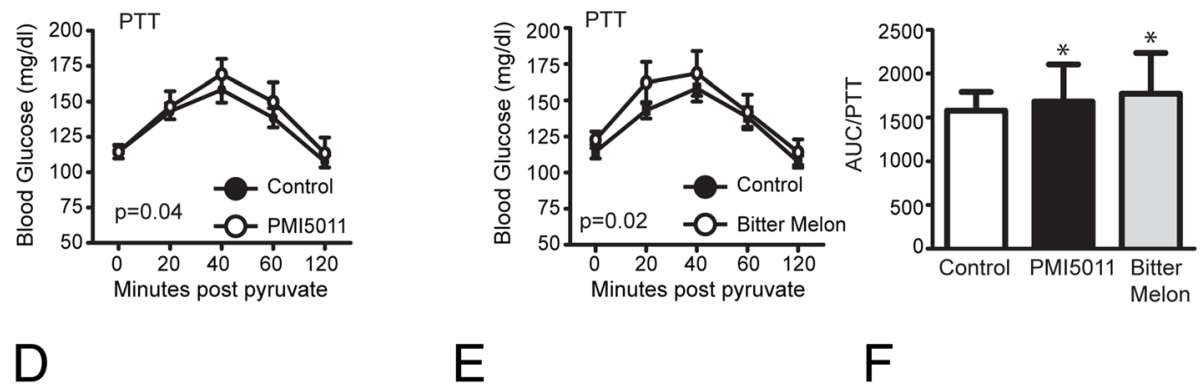

$\mathrm{E}$
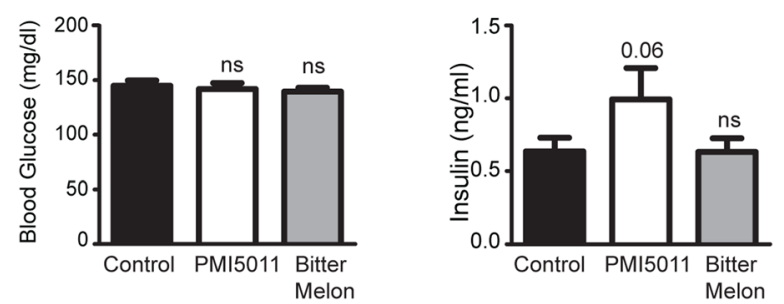

$\mathrm{F}$

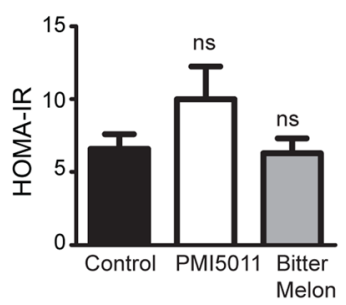

Fig. 3 PMI5011 and bitter melon alter carbohydrate and lipid metabolism in high-fat-fed female mice: PMI5011 and bitter melon supplementation do not result in statistically significant alterations in AUC for GT and ITT $(\mathbf{a}, \mathbf{b})$; however, there was a trend toward higher blood glucose levels at the later time points in the ITT for both PMI5011 and bitter melon (b). Pyruvate tolerance tests showed that both bitter melon and PMI5011 increased hepatic glucose production, consistent with increased gluconeogenesis (c). Neither PMI5011 nor bitter melon induced statistically significant changes in blood glucose (d), although PMI5011 supplementation resulted in a trend $(p=0.06)$ toward elevated fasting insulin (e). Statistically significant modulations were not detected in HOMA-IR (f), although PMI5011 appears to result in non-significant increase in this parameter. Statistical significance was set at $p<0.05$, as determined by repeated measures ANOVA or unpaired two-tailed $t$ test. Variability is expressed as mean \pm SD

insulin (Fig. 3e) that approached statistical significance $(p$ $=0.06)$. Collectively, these data suggest that neither botanical supplement favorably alters glucose homeostasis or insulin sensitivity in female mice challenged with a HFD, with PMI5011 demonstrating a tendency to increase fasting insulin levels despite the lack of a commensurate reduction in fasting glucose. Furthermore, HOMA-IR data suggests that PMI5011 negatively modulates whole-body insulin sensitivity, whereas bitter melon supplementation did not affect HOMA-IR (Fig. 3f).
Effect of PMI5011 and bitter melon on lipid metabolism in female mice

To determine the effect of PMI5011 and bitter melon on blood lipids in high-fat-fed female mice, we assayed total cholesterol, serum triglycerides, and free fatty acids. PMI5011 modestly increased total cholesterol while bitter melon induced a statistically significant increase in total cholesterol (Fig. 4a). Serum triglycerides were significantly increased by PMI5011, whereas bitter melon did not appear to have an effect (Fig. 4b). Both botanicals tended to increase 

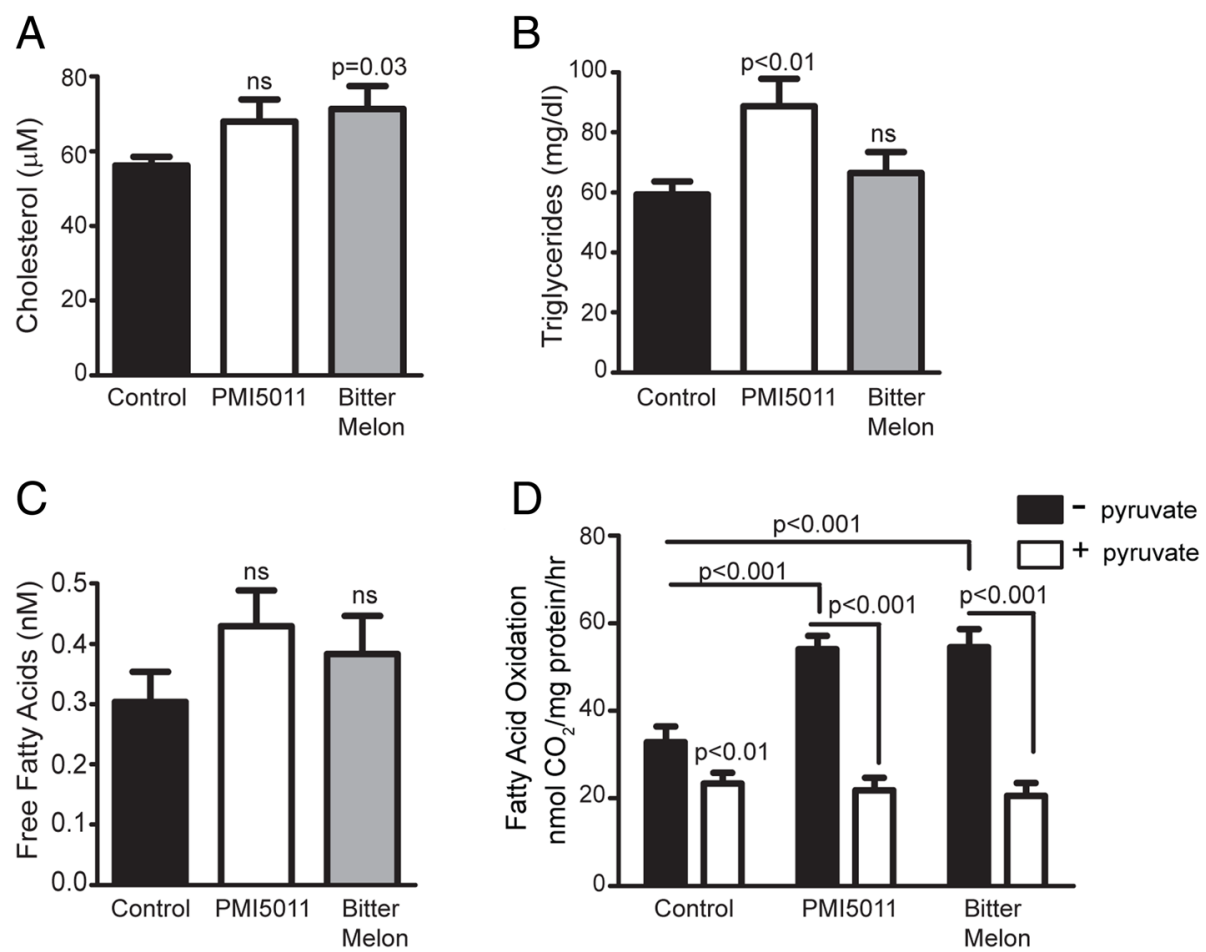

Fig. 4 PMI5011 and bitter melon modulate lipid metabolism in high-fat-fed female mice: Bitter melon induced a statistically significant increase in total cholesterol, while PMI5011 modestly increased total cholesterol (a). Serum triglycerides were significantly increased by PMI5011, but not by bitter melon (b). Both supplements induced non-significant trends toward increased serum free fatty acids (c). Mixed gastrocnemius homogenates exhibited an increase in the rate of fatty acid oxidation in response to PMI5011 and bitter melon supplementation (d). Fatty acid oxidation rates in mixed gastrocnemius homogenates were suppressed when exposed to pyruvate in the female mice supplemented with PMI5011 or bitter melon, indicating enhanced metabolic flexibility in response to changes in nutrient availability (d). Statistical significance was set at $p<0.05$, as determined by unpaired two-tailed $t$ test. Variability is expressed as mean \pm SD

serum free fatty acids, although neither effect was statistically significant (Fig. 4c). To further investigate the effects of PMI5011 and bitter melon on lipid metabolism in females, we assessed fatty acid oxidation rates in mixed gastrocnemius homogenates in response to treatment with these botanicals. Results indicate that both supplements increase the capacity of skeletal muscle to utilize lipid as a metabolic fuel source in response to a high-fat diet, as shown by significant increases in fatty acid oxidation rates compared to controls (Fig. 4d). Moreover, both PMI5011 and bitter melon robustly suppress fatty acid oxidation rates in mixed gastrocnemius homogenates exposed to pyruvate ex vivo as a surrogate for glucose oxidation (Fig. 4d). Although carbohydrate metabolism is not assessed by pyruvate-mediated suppression of fatty acid oxidation, the results indicate that both PMI5011 and bitter melon promote metabolic flexibility in the context of high-fat diet consumption.

\section{Enhanced metabolic flexibility in skeletal muscle in response to PMI5011 and bitter melon supplementation is not mediated by transcriptional regulation}

In order to investigate the biochemical mechanisms underlying the improved metabolic flexibility in skeletal muscle observed in female mice, mRNA and protein abundance of a range of factors controlling fatty acid metabolism were assayed by qRT-PCR and immunoblotting, respectively. Overall, neither PMI5011 nor bitter melon induced changes in the gene expression of transcription factors (Pgc1a, Ppara, Ppard, Pparg) that regulate fatty acid oxidation or mitochondrial function (Cpt1b, Cpt2, Cs). However, PMI5011 increased mRNA and protein levels of CD36 and bitter melon intake is associated with increased CD36 protein levels, suggesting increased fatty acid uptake in the skeletal muscle of the PMI5011 and bitter melon-supplemented females (Fig. 5a, c). Interestingly, the increased fatty acid oxidation rates with botanical supplementation (Fig. 4d) are not associated with increased activation of AMPK or increased insulin responsiveness as measured by AKT phosphorylation (Fig. 5b, c).

\section{Effects of PMI5011 and bitter melon on hepatic gene and protein expression}

The mild elevation in blood glucose in the HFD-fed females (Fig. 3d) and increased blood glucose observed with the pyruvate tolerance test in the botanical-supplemented females (Fig. 3c) prompted us to assay gene and protein 

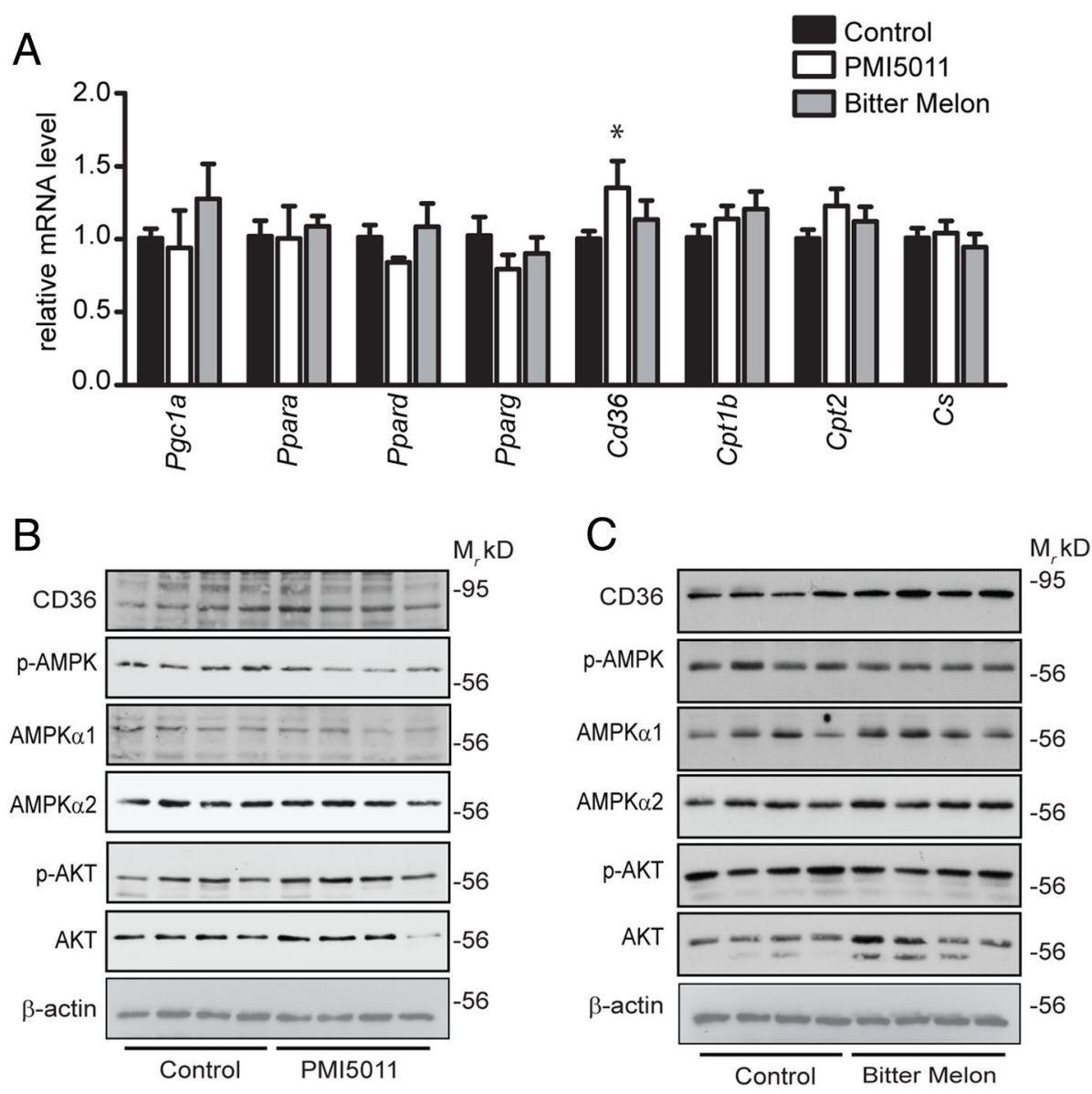

Fig. 5 Botanical supplement-induced enhanced metabolic flexibility in skeletal muscle is not mediated by transcriptional regulation: Neither PMI5011 nor bitter melon alters overall patterns of mRNA expression (a) or protein abundance $(\mathbf{b}, \mathbf{c})$ in biochemical factors regulating fatty acid metabolism or insulin signaling in high-fat-fed female mice. However, both mRNA and protein abundance of CD36 were increased in the skeletal muscle of mice supplemented with PMI5011 (a, b). Statistical significance was set at $p<0.05$, as determined by unpaired two-tailed $t$ test. Variability is expressed as mean \pm SD

expression of factors controlling hepatic glucose and lipid metabolism. Although Pgc1a increases, expression of the lipogenic transcriptional regulator $P g c 1 b$ and markers of mitochondrial function (Cpt1a, Cpt2, Cs) is unchanged (Fig. 6a). De novo lipogenesis (DNL) does not appear to be regulated by either botanical. Although Chrebp1 and Foxo1 levels are modestly upregulated by PMI5011, the botanicals do not alter srebp-1c expression. Moreover, SREBP-1c target genes that regulate DNL (Scd1, Fasn) are not increased by the botanicals or, in the case of Elovl6, are suppressed (Fig. 6b). In contrast, the gene encoding PEPCK (Pck1) is significantly upregulated, consistent with increased gluconeogenesis. However, expression of two other genes regulating gluconeogenesis, $g 6 p c$ and $p c$, is reduced.

To determine if the botanicals altered signaling events controlling hepatic glucose and lipid metabolism, we assayed the phosphorylation status of AMPK, ACC, FoxO1, and AKT as well as the steady state levels of
SREBP-1c with PMI5011 (Fig. 6c) or bitter melon (Fig. 6d) supplementation. Hepatic AMPK activity does not increase in response to supplementation with either botanical, as indicated by diminished AMPK $\alpha 1$ protein expression and unaltered ACC phosphorylation. Additionally, acute insulin-dependent AKT phosphorylation is not enhanced by the botanicals in the female mice. Failure of the botanicals to enhance insulin responsiveness is also reflected in the absence of changes in phosphorylation-dependent downregulation of FoxO1. While SREBP-1c is not regulated by PMI5011, the levels trend upward with bitter melon supplementation.

Effect of PMI5011 and bitter melon on lipid accumulation We next assessed lipid content in the skeletal muscle and liver by histological examination. Analysis by hematoxylin and eosin staining indicated that both botanicals induced changes in lipid accumulation in mixed gastrocnemius muscle and liver (Fig. 7a, c). To assess lipid accumulation 


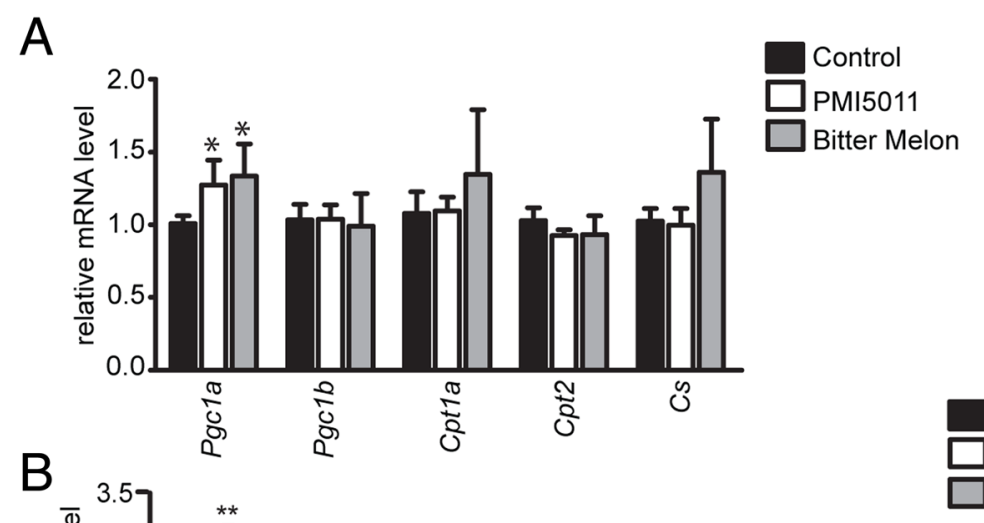

Control

PMI5011

Bitter Melon

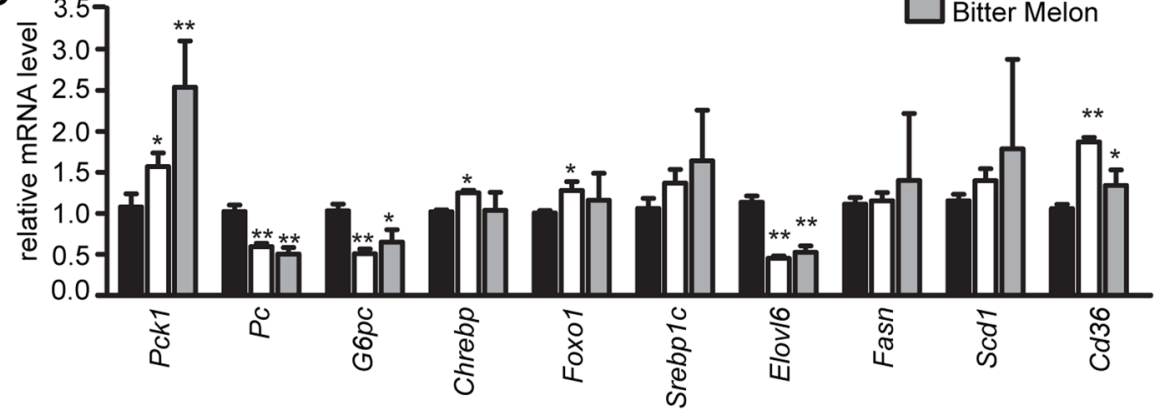

C
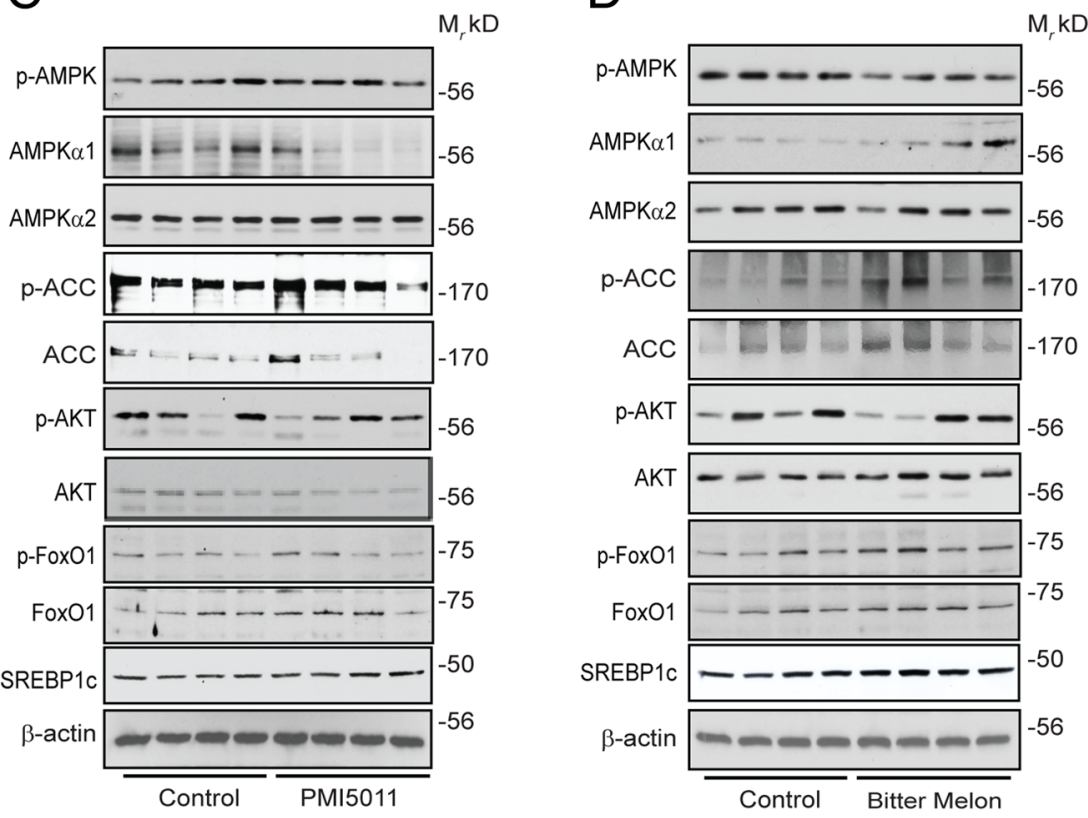

Fig. 6 Effects of PMI5011 and bitter melon on hepatic gene and protein expression in high-fat-fed female mice: Both PMI5011 and bitter melon increased mRNA abundance of Pgcla, but not other markers of lipid metabolism (a). Markers of de novo lipogenesis are not upregulated while Cd36 and a marker of gluconeogenesis (Pck1) are upregulated (b). PMI5011 (c) and bitter melon (d) do not regulate the levels of proteins involved in lipid metabolism or insulin signaling. Statistical significance was set at $p<0.05$, as determined by unpaired two-tailed $t$ test. Variability is expressed as mean \pm SD

quantitatively, we performed triglyceride assays on the liver and mixed gastrocnemius samples. Results showed a reduction in lipid content in mixed gastrocnemius that was statistically significant with PMI5011 but not bitter melon (Fig. 7b). Bitter melon supplementation resulted in a non-significant reduction $(p=0.06)$ in triglyceride content in the liver whereas PMI5011 induced a non-significant increase in hepatic triglyceride levels (Fig. 7d) although lipid accumulation was not readily apparent with H\&E staining on the females fed a high-fat diet alone (Fig. 7a, c). 

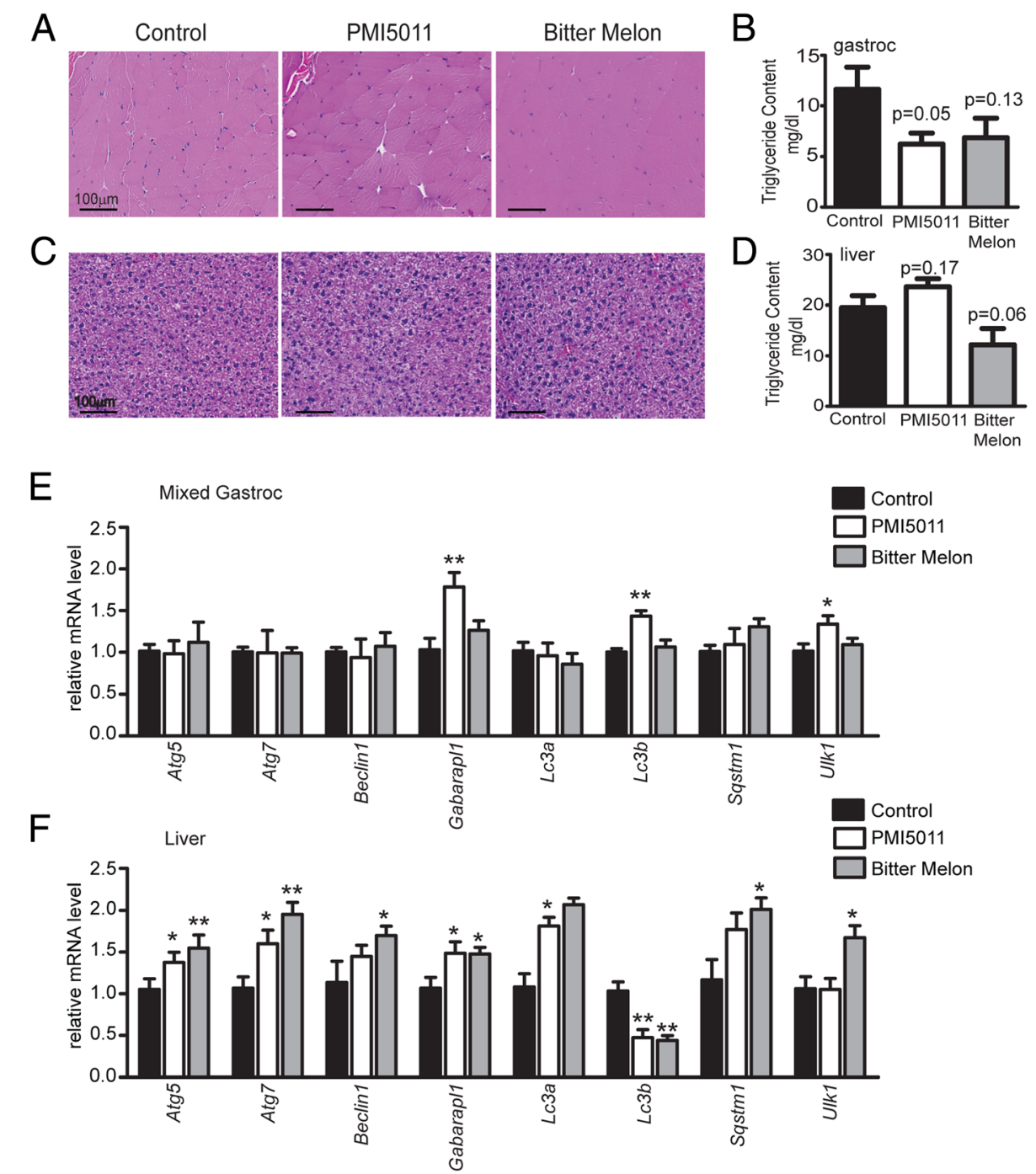

Fig. 7 PMI5011 and bitter melon modulate lipid accumulation in high-fat-fed female mice: H\&E staining indicates that both PMI5011 and bitter melon induce alterations in lipid accumulation in the mixed gastrocnemius muscle and liver $(\mathbf{a}, \mathbf{c})$. Triglyceride assays showed that PMI5011 induced statistically significant reductions in triglyceride content in mixed gastrocnemius muscle (b). Bitter melon resulted in a trend ( $p=0.06$ ) toward reduction in liver triglyceride accumulation whereas PMI5011 induced a non-significant increase in hepatic triglyceride levels although lipid accumulation was not readily apparent with H\&E staining on the females fed a high-fat diet alone (d). PMI5011 supplementation induced some transcriptional regulation in a set of autophagic genes in the skeletal muscle and liver, although this effect was not as pronounced as that observed in response to bitter melon supplementation $(\mathbf{e}, \mathbf{f})$. Statistical significance was set at $p<0.05$, as determined by unpaired two-tailed $t$ test. Variability is expressed as mean $\pm \mathrm{SD}$

Autophagy is an important cellular process that is engaged in response to challenges to energy homeostasis such as fasting and exercise [53]. Moreover, evidence indicates that increased hepatic autophagy is positively associated with an improved serum lipid profile [54] and there is compelling evidence that hepatic lipid storage is regulated by autophagy [55]. Autophagic genes are transcriptionally regulated by nutrient conditions [56]. Thus, we assessed the mRNA levels of a panel of autophagic genes (atg5, atg7, beclin1, gabarapl1, sqstm1, ulk1, lc3a, $l c 3 b)$ in the liver and skeletal muscle. We observed a degree of transcriptional regulation in the muscle and liver by PMI5011 (Fig. 7e, f). However, bitter melon induced robust upregulation in autophagic genes in the liver (Fig. 7f). These results are consistent with reduced lipid accumulation in the liver of the bitter melon-fed female mice compared to those supplemented with PMI5011.

\section{Discussion}

Approximately one third of adults in the USA have obesity-related metabolic syndrome, defined by the presence of insulin resistance, dyslipidemia, hypertension, and visceral obesity [57, 58]. Although metabolic syndrome is typically associated with central/visceral obesity 
in men and post-menopausal women, it is becoming more prevalent in premenopausal women with central obesity associated with increased waist circumference [58]. Thus, it is important to include fertile female rodents in preclinical animal studies designed to test potential therapeutic approaches to combat metabolic syndrome.

In the current study, we sought to determine if dietary supplementation with PMI5011 or bitter melon prior to the onset of high-fat diet-induced obesity prevents development of high-fat diet-related insulin resistance in female C57BL/6 mice. Although the botanicals increase fatty acid oxidation capacity in skeletal muscle, lipid profiles are not improved and early indications of hepatic insulin resistance related to glucose output are observed with botanical supplementation in the female mice. Thus, our results indicate that dietary supplementation with PMI5011 and bitter melon is likely more effective in males than females in preventing high-fat diet-induced insulin resistance. In part, this is due to the female C57BL/6 mouse resistance to high-fat diet-induced obesity or insulin resistance, as found in earlier studies [50-52]. We found that obesity resistance in the female mice is independent of botanical supplementation although dietary intake of PMI5011 increases body weight and percent fat mass in the females compared to the high-fat diet alone. PMI5011-mediated fat accumulation occurs although energy intake and expenditure are comparable to the high-fat diet-fed females. This surprising finding suggests PMI5011 supplementation may increase the efficiency of calorie absorption in the gut, resulting in storage of excess energy in adipose tissue. Interestingly, the rate of body weight gain decreased after 6 weeks on the high-fat diet in all groups and is associated with a striking dissimilarity in energy expenditure due to higher physical activity levels of the female mice compared to previously reported data in male mice [26]. Thus, elevated physical activity may account for resistance to high-fat diet-induced obesity typically observed in the female C57BL/6 mice. It is important to note, however, that in the present study the mice began the high-fat diet at 8 weeks of age. The age of onset of high-fat diet consumption in female C57BL6 mice can be an important factor in determining weight gain [59], and it is possible that the absence of weight gain observed in the females is at least partially accounted for by the age when the high-fat diet was introduced. Nonetheless, sex differences in body weight gain, adiposity, activity, and energy expenditure is a notable finding in the present study and carries implications for future studies aimed at investigating sex as a biological variable in a nutritional context. The data reported herein indicate that sex-related differences in physical activity and energy expenditure can be a determining factor underlying variable responses to dietary intervention and are therefore a major consideration in experimental design and interpretation of results.

Next, we employed several methods to investigate the efficacy of the botanical supplements in modulating insulin sensitivity and glucose homeostasis both systemically and at the individual tissue level. Neither PMI5011 nor bitter melon induced any significant differences in the responses to glucose or insulin tolerance testing, supporting the notion that these botanicals do not enhance glucose disposal in high-fat-fed female mice. This is consistent with the observation that PMI5011 supplementation was associated with a trend toward elevated fasting serum insulin levels despite the absence of any commensurate decrease in fasting glucose. Evaluation of the HOMA-IR, coupled with no increase in skeletal muscle protein kinase B (AKT) activity, further consolidates the interpretation that neither of the botanicals improves whole-body glucose homeostasis in female mice when challenged with a high-fat diet.

We also observed a general pattern of elevated plasma lipid levels in the female mice associated with both PMI5011 and bitter melon supplementation that was absent in previous studies of high-fat-fed male mice [26]. However, we note an absence of any correlation between the botanical-mediated increase in plasma fatty acid levels and adiposity or insulin sensitivity in females, consistent with higher fatty acid levels in women independent of fat mass when compared to men [60]. Importantly, skeletal muscle contributes to whole-body glucose disposal to a greater degree than any other tissue type and insulin resistance related to dysregulation of lipid metabolism in skeletal muscle is a defining characteristic of metabolic syndrome and type 2 diabetes [61]. The upward trend in lipid levels in response to the botanicals is met by an increased capacity in the females to use fatty acids as a fuel source in skeletal muscle. The botanicals promoted a "metabolically flexible" phenotype in skeletal muscle that was reflected in the trend toward a lower respiratory exchange ratio consistent with increased ability to use fatty acids as a fuel source while consuming a high-fat diet. However, analysis of genes and proteins involved in the regulation of lipid metabolism indicates enhanced metabolic flexibility is largely unrelated to transcriptional regulation in skeletal muscle, although PMI5011 induced a significant increase in $c d 36$ mRNA expression. This finding raises the possibility that CD36-mediated fatty acid uptake in skeletal muscle in the females contributes to enhanced fatty acid oxidation with dietary intake of PMI5011. This mechanism may also influence fatty acid metabolism in skeletal muscle of the bitter melon-supplemented females as CD36 protein levels are increased with either botanical.

However, botanical supplementation in the females may be associated with increased hepatic glucose output 
as indicated by higher glucose levels with botanical supplementation at the late time points on the insulin tolerance test, elevated glucose with pyruvate tolerance testing and increased mRNA levels of $p c k 1$ in the liver with botanical supplementation. It is possible that the increased glucose levels at the later time points with botanical supplementation in the insulin tolerance test is due to counterregulatory mechanisms against hypoglycemia since these mechanisms occur in male mice at $80 \mathrm{mg} / \mathrm{dl}$ glucose [62], a level observed in the female mice. Even so, physiological adaptation to defend glucose levels seems an unlikely explanation for the increased glucose output upon pyruvate tolerance testing or the elevated hepatic pck-1 mRNA levels at the end of study.

Insulin mediates hepatic glucose output by regulating transcription of the rate-determining enzymes in gluconeogenesis: cytosolic phosphenolpyruvate carboxykinase, encoded by Pck1 and the catalytic subunit of glucose6-phosphatase encoded by G6pc, which is also rate-limiting in glycogenolysis (reviewed in [63]). Insulin-dependent phosphorylation of AKT suppresses Pck1 and G6pc via regulation of FoxO1 and PGC- $1 \alpha$ activity. At the same time, insulin signaling is associated with increased hepatic de novo lipogenesis (DNL) via ChREBP and SREBP-1c transcriptional activity [64]. Botanical supplementation does not significantly affect expression of key transcriptional regulators of DNL at the gene or protein level, and expression of the fatty acid elongase gene elovl6, a target of SREBP-1 that catalyzes long chain fatty acid formation, is suppressed, supporting decreased DNL. However, the effect of PMI5011 and bitter melon on the balance between glucose output and lipid synthesis in the liver appears to be complex as triglyceride levels trend upward with PMI5011 and are unchanged with bitter melon.

Pathway-selective hepatic insulin resistance is proposed to explain the failure of insulin to suppress glucose production but support lipogenesis and liver fat accumulation [65]. However, hepatic triglycerides are primarily derived from nonesterified fatty acids (NEFAs) rather than DNL [66] and re-esterification of NEFAs is driven by substrate availability independent of insulin signaling or transcriptional changes related to lipogenesis [67]. Our data is consistent with a model of botanical-mediated early pathway-selective insulin resistance in the liver characterized by a failure of insulin signaling to suppress glucose output. Unlike previous studies in male mice, the botanicals do not enhance insulin signaling in the females. Thus, DNL is not increased with dietary botanical supplementation when compared to the HFD alone. Increased uptake of NEFAs with the high-fat diet is supported by the increased Cd36 expression and the modest upregulation of triglycerides, primarily for PMI5011 supplementation. Thus, increased hepatic glucose output in response to the botanicals raises concerns about possible early adverse effects of the botanicals on glucose metabolism in the high-fat-fed females.

Despite evidence suggesting that supplementation with PMI5011 and bitter melon may adversely affect hepatic function, we found that there were some advantageous effects of the supplements on ectopic lipid accumulation in the skeletal muscle and liver. In the skeletal muscle, PMI5011 significantly reduced triglyceride accumulation while bitter melon induced a downward trend, consistent with enhanced fatty acid oxidation in the skeletal muscle. In the liver, dietary intake of bitter melon decreased triglyceride content to a level that approached statistical significance $(p=0.06)$ while PMI5011 was associated with increased hepatic triglycerides. Remarkably, modulation of lipid accumulation in these tissues was closely associated with transcriptional regulation of autophagic genes with the most robust response elicited by bitter melon in the liver. Transcriptional regulation of autophagy is regulated by more than 20 transcription factors [56]. Our findings are the first to identify bitter melon-mediated transcriptional regulation of hepatic autophagy. Interestingly, upregulation of gamma-aminobutyric acid receptor-associated protein-1 (Gabarapl1), which encodes a ubiquitin-like protein associated with autophagic vesicles, was first identified as an estrogen-regulated gene [68]. Gabarapl1 is most robustly upregulated in skeletal muscle in the PMI5011supplemented females where estrogen plays an important role in skeletal muscle quality in males [69] as well as females.

\section{Conclusion}

The more pronounced effect of PMI5011 supplementation on improving insulin sensitivity and reducing ectopic lipid accumulation in the skeletal muscle and liver previously reported in males on a high-fat diet compared to females indicates there are sex-related differences in the potential benefits of dietary intake of PMI5011 in preventing risk factors for metabolic syndrome. Alternatively, the absence of any evidence of high-fat diet-induced obesity or insulin resistance in the females raises the possibly that PMI5011 and bitter melon are effective only in the presence of obesity-related insulin resistance as observed in our previous animal studies in male mice $[25,26]$ as well as in vitro models of insulin resistance in skeletal muscle [22, 24, 48]. In that case, PMI5011 and bitter melon may be effective in females that develop insulin resistance with obesity. Although our current study does not differentiate between these two possibilities, our data supporting early selective hepatic insulin resistance related to glucose production with PMI5011 or bitter melon dietary supplementation underscores the potential for untoward effects of botanical supplementation in females and the importance of considering sex-related variations in metabolism and metabolic responses to dietary supplementation. 


\section{Additional files}

Additional file 1: Antibody Information. (PDF $13 \mathrm{~kb}$ )

Additional file 2: Supporting Information Related to Gene Expression Analysis. (PDF $81 \mathrm{~kb}$ )

\section{Abbreviations}

ACC: Acetyl-CoA carboxylase; AKT: Protein kinase B; AMPK: AMP-activated protein kinase; CPT-1: Carnitine palmitoyltransferase I; DNL: De novo lipogenesis; HFD: High-fat diet; HOMA-IR: Homeostatic model assessment for insulin resistance; IL-6: Interleukin-6; IRS-1: Insulin receptor substrate-1; JNK: c-Jun N-terminal kinase; LFD: Low-fat diet; MetS: Metabolic syndrome; PEPCK: Phosphoenolpyruvate carboxykinase; SOCS-3: Suppressor of cytokine signaling-3; TNF-a: Tumor necrosis factor-alpha

\section{Funding}

This research is supported by P50AT002776 (NCCIH), NIH8 1P30GM118430-01 (NIGMS, COBRE), and P30 DK072476 (NIDDK, NORC).

\section{Availability of data and materials}

The data supporting the conclusions of this article are included within the article and the additional files (Additional files 1 and 2).

\section{Authors' contributions}

YY and TM contributed to the animal care, sample collection, data, and statistical analysis. SF, DMR, and ZEF contributed to the data analysis and interpretation. DMR, WTC, and ZEF contributed to the experimental design. SF and ZEF wrote the manuscript. All authors read and approved the final draft.

\section{Ethics approval}

All animal experiments were conducted in accordance with the National Institutes of Health Guide for the Care and Use of Laboratory Animals (8th edition) and approved by the Pennington Biomedical Research Center Animal Care and Use Committee (protocol \#922).

\section{Consent for publication}

Not applicable.

\section{Competing interests}

The authors declare that they have no competing interests.

\section{Publisher's Note}

Springer Nature remains neutral with regard to jurisdictional claims in published maps and institutional affiliations.

\section{Author details}

${ }^{1}$ Pennington Biomedical Research Center, Louisiana State University System, Baton Rouge, LA 70808, USA. ${ }^{2}$ School of Kinesiology, University of Louisiana at Lafayette, Lafayette, LA 70506, USA. ${ }^{3}$ Biotech Center, Rutgers University, New Brunswick, NJ 08901, USA.

Received: 31 May 2018 Accepted: 27 August 2018

Published online: 12 September 2018

\section{References}

1. Aguilar M, Bhuket T, Torres S, Liu B, Wong RJ. Prevalence of the metabolic syndrome in the United States, 2003-2012. JAMA. 2015;313(19):1973-4.

2. Moore JX, Chaudhary N, Akinyemiju T. Metabolic syndrome prevalence by race/ethnicity and sex in the United States, National Health and Nutrition Examination Survey, 1988-2012. Prev Chronic Dis. 2017;14:E24.

3. Park YW, Zhu S, Palaniappan L, Heshka S, Carnethon MR, Heymsfield SB. The metabolic syndrome: prevalence and associated risk factor findings in the US population from the Third National Health and Nutrition Examination Survey, 1988-1994. Arch Intern Med. 2003;163(4):427-36.

4. Johansen D, Stocks T, Jonsson H, Lindkvist B, Bjorge T, Concin H, Almquist M, Haggstrom C, Engeland A, Ulmer $\mathrm{H}$, et al. Metabolic factors and the risk of pancreatic cancer: a prospective analysis of almost 580,000 men and women in the Metabolic Syndrome and Cancer Project. Cancer Epidemiol Biomark Prev. 2010;19(9):2307-17.

5. Mottillo S, Filion KB, Genest J, Joseph L, Pilote L, Poirier P, Rinfret S, Schiffrin EL, Eisenberg MJ. The metabolic syndrome and cardiovascular risk a systematic review and meta-analysis. J Am Coll Cardiol. 2010;56(14): 1113-32.

6. Singh AK, Kari JA. Metabolic syndrome and chronic kidney disease. Curr Opin Nephrol Hypertens. 2013;22(2):198-203.

7. Stocks T, Bjorge T, Ulmer H, Manjer J, Haggstrom C, Nagel G, Engeland A, Johansen D, Hallmans G, Selmer R, et al. Metabolic risk score and cancer risk: pooled analysis of seven cohorts. Int J Epidemiol. 2015;44(4):1353-63.

8. Iyer A, Kauter K, Brown L. Gender differences in metabolic syndrome: a key research issue? Endocr Metab Immune Disord Drug Targets. 2011;11(3): 182-8.

9. Rochlani Y, Pothineni NV, Mehta JL. Metabolic syndrome: does it differ between women and men? Cardiovasc Drugs Ther. 2015;29(4):329-38.

10. Dallongeville J, Cottel D, Arveiler D, Tauber JP, Bingham A, Wagner A, Fauvel J, Ferrieres J, Ducimetiere P, Amouyel P. The association of metabolic disorders with the metabolic syndrome is different in men and women. Ann Nutr Metab. 2004;48(1):43-50.

11. Chen $\mathrm{CH}$, Lin KC, Tsai ST, Chou P. Different association of hypertension and insulin-related metabolic syndrome between men and women in 8437 nondiabetic Chinese. Am J Hypertens. 2000;13(7):846-53.

12. Dalle Grave R, Calugi S, Centis E, Marzocchi R, El Ghoch M, Marchesini G. Lifestyle modification in the management of the metabolic syndrome: achievements and challenges. Diab Metab Syndr Obes. 2010;3:373-85.

13. Pladevall M, Riera-Guardia N, Margulis AV, Varas-Lorenzo C, Calingaert B, Perez-Gutthann S. Cardiovascular risk associated with the use of glitazones, metformin and sufonylureas: meta-analysis of published observational studies. BMC Cardiovasc Disord. 2016;16:14.

14. Herman WH. The global agenda for the prevention of type 2 diabetes. Nutr Rev. 2017;75(suppl 1):13-8.

15. Ranasinghe $P$, Mathangasinghe $Y$, Jayawardena R, Hills AP, Misra A. Prevalence and trends of metabolic syndrome among adults in the asiapacific region: a systematic review. BMC Public Health. 2017;17(1):101.

16. Cohen PA. American roulette--contaminated dietary supplements. N Engl J Med. 2009;361(16):1523-5.

17. Cohen PA. Hazards of hindsight--monitoring the safety of nutritional supplements. N Engl J Med. 2014;370(14):1277-80.

18. Yamamoto N, Kanemoto Y, Ueda M, Kawasaki K, Fukuda I, Ashida H. Antiobesity and anti-diabetic effects of ethanol extract of Artemisia princeps in C57BL/6 mice fed a high-fat diet. Food Funct. 2011;2(1):45-52.

19. Choi Y, Yanagawa Y, Kim S, Whang WK, Park T. Artemisia iwayomogi extract attenuates high-fat diet-induced obesity by decreasing the expression of genes associated with adipogenesis in mice. Evid Based Complement Alternat Med. 2013;2013:915953.

20. Wang ZQ, Zhang XH, Yu Y, Tipton RC, Raskin I, Ribnicky D, Johnson W, Cefalu WT. Artemisia scoparia extract attenuates non-alcoholic fatty liver disease in diet-induced obesity mice by enhancing hepatic insulin and AMPK signaling independently of FGF21 pathway. Metab Clin Exp. 2013; 62(9):1239-49.

21. Swanston-Flatt SK, Flatt PR, Day C, Bailey CJ. Traditional dietary adjuncts for the treatment of diabetes mellitus. Proc Nutr Soc. 1991;50(3):641-51.

22. Kheterpal I, Coleman L, Ku G, Wang ZQ, Ribnicky D, Cefalu WT. Regulation of insulin action by an extract of Artemisia dracunculus $L$. in primary human skeletal muscle culture: a proteomics approach. Phytother Res. 2010;24(9): 1278-84.

23. Obanda DN, Hernandez A, Ribnicky D, Yu Y, Zhang XH, Wang ZQ, Cefalu WT. Bioactives of Artemisia dracunculus L. mitigate the role of ceramides in attenuating insulin signaling in rat skeletal muscle cells. Diabetes. 2012;61(3): 597-605.

24. Wang ZQ, Ribnicky D, Zhang XH, Raskin I, Yu Y, Cefalu WT. Bioactives of Artemisia dracunculus $L$ enhance cellular insulin signaling in primary human skeletal muscle culture. Metabolism. 2008;57(7 Suppl 1):S58-64.

25. Wang ZQ, Ribnicky D, Zhang XH, Zuberi A, Raskin I, Yu Y, Cefalu WT. An extract of Artemisia dracunculus $L$. enhances insulin receptor signaling and modulates gene expression in skeletal muscle in KK-A(y) mice. J Nutr Biochem. 2011;22(1):71-8.

26. Yu Y, Mendoza T, Ribnicky D, Poulev A, Noland RC, Mynatt RL, Raskin I, Cefalu WT, Floyd ZE. An extract of Russian tarragon prevents obesity-related ectopic lipid accumulation. Mol Nutr Food Res. 2018;62(8):e1700856. 
27. Ma C, Yu H, Xiao Y, Wang H. Momordica charantia extracts ameliorate insulin resistance by regulating the expression of SOCS-3 and JNK in type 2 diabetes mellitus rats. Pharm Biol. 2017;55(1):2170-7.

28. Mahwish SF, Arshad MS, Nisa MU, Nadeem MT, Arshad MU. Hypoglycemic and hypolipidemic effects of different parts and formulations of bitter gourd (Momordica Charantia). Lipids Health Dis. 2017;16(1):211.

29. Willcox DC, Scapagnini G, Willcox BJ. Healthy aging diets other than the Mediterranean: a focus on the Okinawan diet. Mech Ageing Dev. 2014;136-137: 148-62.

30. Sridhar MG, Vinayagamoorthi R, Arul Suyambunathan V, Bobby Z, Selvaraj N. Bitter gourd (Momordica charantia) improves insulin sensitivity by increasing skeletal muscle insulin-stimulated IRS-1 tyrosine phosphorylation in high-fat-fed rats. Br J Nutr. 2008;99(4):806-12.

31. Han JH, Tuan NQ, Park MH, Quan KT, Oh J, Heo KS, Na M, Myung CS. Cucurbitane triterpenoids from the fruits of Momordica charantia improve insulin sensitivity and glucose homeostasis in streptozotocin-induced diabetic mice. Mol Nutr Food Res. 2018:62(7):e1700769.

32. Bai J, Zhu Y, Dong Y. Bitter melon powder protects against obesityassociated fatty liver disease by improving colonic microenvironment in rats with high-fat diet-induced obesity. Biomed Environ Sci. 2017;30(8):611-5.

33. Xu J, Cao K, Li Y, Zou X, Chen C, Szeto IM, Dong Z, Zhao Y, Shi Y, Wang J, et al. Bitter gourd inhibits the development of obesity-associated fatty liver in C57BL/6 mice fed a high-fat diet. J Nutr. 2014;144(4):475-83.

34. Shih CC, Shlau MT, Lin CH, Wu JB. Momordica charantia ameliorates insulin resistance and dyslipidemia with altered hepatic glucose production and fatty acid synthesis and AMPK phosphorylation in high-fat-fed mice. Phytother Res. 2014;28(3):363-71.

35. Matsui S, Yamane T, Takita T, Oishi Y, Kobayashi-Hattori K. The hypocholesterolemic activity of Momordica charantia fruit is mediated by the altered cholesterol- and bile acid-regulating gene expression in rat liver. Nutr Res. 2013;33(7):580-5

36. Schmidt B, Ribnicky DM, Poulev A, Logendra S, Cefalu WT, Raskin I. A natural history of botanical therapeutics. Metabolism. 2008;57(7 Suppl 1):S3-9.

37. Ribnicky DM, Poulev A, Watford M, Cefalu WT, Raskin I. Antihyperglycemic activity of Tarralin, an ethanolic extract of Artemisia dracunculus $L$ Phytomedicine. 2006;13(8):550-7.

38. Ribnicky DM, Kuhn P, Poulev A, Logendra S, Zuberi A, Cefalu WT, Raskin I. Improved absorption and bioactivity of active compounds from an antidiabetic extract of Artemisia dracunculus L. Int J Pharm. 2009;370(1-2):87-92.

39. Zuberi AR. Strategies for assessment of botanical action on metabolic syndrome in the mouse and evidence for a genotype-specific effect of Russian tarragon in the regulation of insulin sensitivity. Metabolism. 2008; 57(7 Suppl 1):S10-5.

40. Logendra S, Ribnicky DM, Yang H, Poulev A, Ma J, Kennelly EJ, Raskin I. Bioassay-guided isolation of aldose reductase inhibitors from Artemisia dracunculus. Phytochemistry. 2006;67(14):1539-46.

41. Prendergast BJ, Onishi KG, Zucker I. Female mice liberated for inclusion in neuroscience and biomedical research. Neurosci Biobehav Rev. 2014;40:1-5.

42. Service USDoAAR: Nutrient intakes from food: mean amounts of consumed per individual, by Gender and Age, What We Eat in America, NHANES 20092010. 2012.

43. Matthews DR, Hosker JP, Rudenski AS, Naylor BA, Treacher DF, Turner RC. Homeostasis model assessment: insulin resistance and beta-cell function from fasting plasma glucose and insulin concentrations in man. Diabetologia. 1985:28(7):412-9.

44. Folch J, Lees M, Sloane Stanley GH. A simple method for the isolation and purification of total lipides from animal tissues. J Biol Chem. 1957;226(1):497-509.

45. Noland RC, Woodlief TL, Whitfield BR, Manning SM, Evans JR, Dudek RW, Lust RM, Cortright RN. Peroxisomal-mitochondrial oxidation in a rodent model of obesity-associated insulin resistance. Am J Physiol Endocrinol Metab. 2007;293(4):E986-E1001.

46. Hulver MW, Berggren JR, Cortright RN, Dudek RW, Thompson RP, Pories WJ, MacDonald KG, Cline GW, Shulman Gl, Dohm GL, et al. Skeletal muscle lipid metabolism with obesity. Am J Physiol Endocrinol Metab. 2003;284(4):E741-7.

47. Wang ZQ, Floyd ZE, Qin J, Liu X, Yu Y, Zhang XH, Wagner JD, Cefalu WT. Modulation of skeletal muscle insulin signaling with chronic caloric restriction in cynomolgus monkeys. Diabetes. 2009;58(7):1488-98.

48. Kheterpal I, Scherp P, Kelley L, Wang Z, Johnson W, Ribnicky D, Cefalu WT. Bioactives from Artemisia dracunculus L. enhance insulin sensitivity via modulation of skeletal muscle protein phosphorylation. Nutrition. 2014; 30(7-8 Suppl):S43-51.
49. Vandanmagsar B, Haynie KR, Wicks SE, Bermudez EM, Mendoza TM, Ribnicky D, Cefalu WT, Mynatt RL. Artemisia dracunculus L. extract ameliorates insulin sensitivity by attenuating inflammatory signalling in human skeletal muscle culture. Diabetes Obes Metab. 2014;16(8):728-38.

50. Benz V, Bloch M, Wardat S, Bohm C, Maurer L, Mahmoodzadeh S, Wiedmer P, Spranger J, Foryst-Ludwig A, Kintscher U. Sexual dimorphic regulation of body weight dynamics and adipose tissue lipolysis. PLoS One. 2012;7(5):e37794.

51. Pettersson US, Walden TB, Carlsson PO, Jansson L, Phillipson M. Female mice are protected against high-fat diet induced metabolic syndrome and increase the regulatory T cell population in adipose tissue. PLoS One. 2012; 7(9):e46057.

52. Yang Y, Smith DL Jr, Keating KD, Allison DB, Nagy TR. Variations in body weight, food intake and body composition after long-term high-fat diet feeding in C57BL/6J mice. Obesity (Silver Spring). 2014;22(10):2147-55.

53. Smith BK, Marcinko K, Desjardins EM, Lally JS, Ford RJ, Steinberg GR. Treatment of nonalcoholic fatty liver disease: role of AMPK. Am J Physio Endocrinol Metab. 2016;311(4):E730-e740.

54. Sun L, Zhang S, Yu C, Pan Z, Liu Y, Zhao J, Wang X, Yun F, Zhao H, Yan S, et al. Hydrogen sulfide reduces serum triglyceride by activating liver autophagy via the AMPK-mTOR pathway. Am J Physiol Endocrinol Metab. 2015;309(11):E925-35.

55. Singh R, Kaushik S, Wang Y, Xiang Y, Novak I, Komatsu M, Tanaka K, Cuervo AM, Czaja MJ. Autophagy regulates lipid metabolism. Nature. 2009; 458(7242):1131-5

56. Fullgrabe J, Ghislat G, Cho DH, Rubinsztein DC. Transcriptional regulation of mammalian autophagy at a glance. J Cell Sci. 2016;129(16):3059-66.

57. Beltran-Sanchez H, Harhay MO, Harhay MM, McElligott S. Prevalence and trends of metabolic syndrome in the adult U.S. population, 1999-2010. J Am Coll Cardiol. 2013;62(8):697-703.

58. Kuk JL, Ardern Cl. Age and sex differences in the clustering of metabolic syndrome factors: association with mortality risk. Diabetes Care. 2010;33(11): 2457-61.

59. Salinero $A E$, Anderson BM, Zuloaga KL. Sex differences in the metabolic effects of diet-induced obesity vary by age of onset. Int J Obes. 2018;42(5): 1088-91.

60. Karpe F, Dickmann JR, Frayn KN. Fatty acids, obesity, and insulin resistance: time for a reevaluation. Diabetes. 2011:60(10):2441-9.

61. DeFronzo RA, Tripathy D. Skeletal muscle insulin resistance is the primary defect in type 2 diabetes. Diabetes Care. 2009;32(Suppl 2):S157-63.

62. McGuinness OP, Ayala JE, Laughlin MR, Wasserman DH. NIH experiment in centralized mouse phenotyping: the Vanderbilt experience and recommendations for evaluating glucose homeostasis in the mouse. Am J Physiol Endocrinol Metab. 2009;297(4):E849-55.

63. Lin HV, Accili D. Hormonal regulation of hepatic glucose production in health and disease. Cell Metab. 2011;14(1):9-19.

64. Sanders FW, Griffin JL. De novo lipogenesis in the liver in health and disease: more than just a shunting yard for glucose. Biol Rev Camb Philos Soc. 2016;91(2):452-68.

65. Otero YF, Stafford JM, McGuinness OP. Pathway-selective insulin resistance and metabolic disease: the importance of nutrient flux. J Biol Chem. 2014; 289(30):20462-9.

66. Donnelly KL, Smith Cl, Schwarzenberg SJ, Jessurun J, Boldt MD, Parks EJ. Sources of fatty acids stored in liver and secreted via lipoproteins in patients with nonalcoholic fatty liver disease. J Clin Invest. 2005;115(5):1343-51.

67. Vatner DF, Majumdar SK, Kumashiro N, Petersen MC, Rahimi Y, Gattu AK, Bears M, Camporez JP, Cline GW, Jurczak MJ, et al. Insulin-independent regulation of hepatic triglyceride synthesis by fatty acids. Proc Natl Acad Sci U S A. 2015;112(4):1143-8.

68. Vernier-Magnin S, Muller S, Sallot M, Radom J, Musard JF, Adami P, Dulieu P, Remy-Martin JP, Jouvenot M, Fraichard A. A novel early estrogen-regulated gene gec1 encodes a protein related to GABARAP. Biochem Biophys Res Commun. 2001;284(1):118-25.

69. Cooke PS, Nanjappa MK, Ko C, Prins GS, Hess RA. Estrogens in male physiology. Physiol Rev. 2017;97(3):995-1043. 